\title{
Epicardial fat thickness and cardiovascular involvements.
}

\author{
Sevket Balta, Mustafa Demır, Ali Osman Yıldırım, Sait Demırkol, Cengiz Ozturk, Turgay Celık
}

Department of Cardiology, Gulhane Medical Academy Ankara/TURKEY

DOI: http://dx.doi.org/10.4314/ahs.v15i4.40

Cite as: Balta S, Demur M, Yuldurm AO, Demurkol S, Ozturk C, Cellk T. Epicardial fat thickness and cardiovascular involvements. Afri Health Sci. 2015;15(4):1354-5. bttp:/ / dx.doi.org/10.4314/abs.v15i4.40

\section{Dear Editor,}

We have read the article " Epicardial fat thickness(EFT) in patients with rheumatoid arthritis" written by Erdem et al. with a great interest. ${ }^{1}$ The authors aimed to explain the relationship between epicardial fat thickness and clinical and echocardiographic parameters in patients with rheumatoid arthritis. They concluded that EFT as an indicator of cardiovascular involvement was higher in rheumatoid arthritis patients. Thanks to the authors for their contribution of the present study which is successfully designed and documented.

Epicardial tissue makes active endocrine organ function which produces several markers involved in oxidative stress, endothelial dysfunction, atherosclerosis and inflammation, ${ }^{2,3}$. Increased epicardial adiposity can lead to cardiovascular diseases due to endocrine actions that include increased production of reactive oxygen species, atherogenic and inflammatory cytokines. Various studies have highlighted EFT is also clinically related to hypertension, type 2 diabetes, metabolic syndrome, dyslipidemia, nonalcoholic fatty liver disease, and chronic kidney disease. EFT is also a cardiometabolic risk factor in various inflammatory diseases and is also independently associated with psoriasis. ${ }^{4}$ EFT may be included among the clinical parameters associated with

\footnotetext{
Corresponding author:

Sevket Balta,

Department of Cardiology

Gulhane School of Medicine,

Tevfik Saglam St., 06018 Etlik-Ankara, Turkey

Tel: +90-312-3044281

Fax: +90-312-3044250

E-mail: drsevketb@gmail.com, sevketb@gata.edu.tr
}

OSA severity. The association of EFT with OSA, both cardiovascular risk factors, is independent of obesity as defined by classical measures ${ }^{5}$.

Echocardiographic epicardial fat measurement in both clinical and research scenarios has several advantages, including its low cost, easy accessibility, rapid applicability, and good reproducibility. However, more evidence is necessary to evaluate whether echocardiographic epicardial fat thickness may become a routine way of assessing cardiovascular risk in a clinical setting ${ }^{6}$. In present study, EFT was calculated on the free wall of the right ventricle in the still images obtained at end diastole the parasternal long-axis view, using the aortic annulus as an anatomic reference. However, second image as short axis view may be add useful information about EFT values.Then, the mean value of two images obtained in the parasternal long-axis and short-axis views should be measured.Secondly, the echocardiography method might not be the optimal technique for quantification of epicardial tissue. The gold standard in evaluating EFT is magnetic resonance imaging (MRI); the lack of MRI use is one of the limitations of the present study. After that, because echocardiography measures EFT linearly, echocardiographic EFT may not reflect the total epicardial fat volume exactly. EFT has a 3-dimensional distribution and two-dimensional echocardiography cannot give adequate window of all cardiac segments especially in obese subjects and is highly dependent on acoustic windows ${ }^{2}$. In this point of view, it would be better to give interobserver and intraobserver variability for EAT measurement in the current study ${ }^{7}$. As a conclusion, EFT may provide information to clinicians about the systemic inflammation. So, we believe that these findings will evaluate further studies about EFT on cardiovascular risk in systemic inflammatory disease patients. 


\section{Conflict of interest:}

There is no conflict of interests

\section{References}

1. Fatma E, Bunyamin K, Savas S, Mehmet U, Selma Y, Ismail B, et al. Epicardial fat thickness in patients with rheumatoid arthritis. Afr Health Sci. 2015 Jun;15(2):489_ 95.

2. Balta S, Demirkol S, Kurt Ö, Sarlak H, Akhan M. Epicardial adipose tissue measurement: inexpensive, easy accessible and rapid practical method. Anadolu Kardiyol Derg. 2013 Sep 10;13(6):611.

3. Katsiki N, Mikhailidis DP, Wierzbicki AS. Epicardial fat and vascular risk: a narrative review. Curr Opin Cardiol. 2013 Jul;28(4):458-63.
4. Balta I, Balta S, Ozturk C, Demirkol S, Demir M. Epicardial fat thickness in psoriasis patients. Dermatology. 2014 Jan 8;228(2):132-3.

5. Mariani S, Fiore D, Barbaro G, Basciani S, Saponara M, D'Arcangelo E, et al. Association of epicardial fat thickness with the severity of obstructive sleep apnea in obese patients. Int J Cardiol. 2013 Sep 1;167(5):2244-9. 6. Iacobellis G, Willens HJ. Echocardiographic epicardial fat: a review of research and clinical applications. J Am Soc Echocardiogr. 2009 Dec;22(12):1311-9; quiz 1417-8.

7. Şengül C, Özveren O. Epicardial adipose tissue: a review of physiology, pathophysiology, and clinical applications. Anadolu Kardiyol Derg. 2013 May 6;13(3):261-5. 